\title{
High data rate and ultra-compact optical encoder based on 2D linear photonic crystal ring resonator
}

Mayur Kumar Chhipa

Koneru Lakshmaiah Education Foundation

\section{B.T.P. Madhav}

Koneru Lakshmaiah Education Foundation

Bhuvneshwer Suthar ( $\sim$ bhuvneshwer@gmail.com )

MLB Govt. College, Nokha, Bikaner https://orcid.org/0000-0002-0441-9234

Vijay Janyani

MNIT Jaipur: Malaviya National Institute of Technology

\section{Research Article}

Keywords: Optical encoder, band gap structures, defects, Photonic crystal, photonic crystal ring resonator, PWE method

Posted Date: March 23rd, 2021

DOI: https://doi.org/10.21203/rs.3.rs-320802/v1

License: (1) (1) This work is licensed under a Creative Commons Attribution 4.0 International License. Read Full License 


\title{
High data rate and ultra-compact optical encoder based on 2D linear photonic crystal ring resonator
}

\author{
Mayur Kumar Chhipa ${ }^{1}$, B.T.P. Madhav ${ }^{1}$, Bhuvneshwer Suthar ${ }^{2, *}$, Vijay Janyani $^{3}$ \\ ${ }^{1}$ Department of Electronics and Communication Engineering, Koneru Lakshmaiah Education \\ Foundation, Vaddeswaram, Guntur, Andhra Pradesh, 522502 India \\ ${ }^{2}$ Department of Physics, M.L.B. Govt. College, Nokha 334803, Bikaner, Rajasthan, India \\ ${ }^{3}$ Department of Electronics \& Comm. Engineering, Malaviya National Institute of Technology, \\ Jaipur, India \\ *Corresponding Author's Email: bhuvneshwer@gmail.com
}

\begin{abstract}
In the present work, a high-speed optical encoder is proposed based on two-dimensional photonic crystal ring resonator (2D-PCRR) using coupled mode theory and resonance effect. Square shaped ring resonator, couplings rods and several waveguides have been utilized in the proposed structure. Silicon rods in air structure has been designed with rod radius of 0.1a and lattice constant $0.540 \mathrm{~nm}$. The photonic band gap is being calculated using plane wave expansion method and finite-difference-time-domain method to analyze the performance characteristics of optical encoder like: transmission spectra, electric field view, contrast ratio, delay time, response time etc. The operating wavelength of structure is $1550 \mathrm{~nm}$, to perform encoder operation where only one input port is activated at a time while other input ports are inactivated and accordingly equivalent binary encoded signal is produced at output ports. The proposed encoder is designed with fast response time $222.76 \mathrm{fs}$, high data rate of $4.48 \mathrm{Tbps}$ and ultra-compact size of $140.84 \mu \mathrm{m}^{2}$. Hence the proposed device is suitable for high-speed optical computation, photonic integrated devices and high speed optical integrated circuits.
\end{abstract}


Keywords: Optical encoder; band gap structures; defects; Photonic crystal; photonic crystal ring resonator; PWE method

\section{Introduction}

Integration of high-speed light devices and advance results from new technologies are very important factors affecting the development of integrated optical devices for optical communication networks and photonic integrated circuits. Every day, the increasing demand for higher bandwidth needs signal processing systems at high-speed. In conventional electronics, the signal processing speed is limited due to slow speed and huge power consumption. All-optical signal processing is an alternate way to increase signal processing speed at very low power consumption [1]. By using the new generation of optical devices to perform the all-optical logic operations with rapid transfer, storage, high processing speed and high data rate are advantages to the realization of photonic integrated technology in comparison to the issues discussed in conventional electronic devices. Tremendous research work is going on designing the miniaturized photonic components for integrated circuits. In general, photonic integrated circuits (PICs), are the combination of various photonics technologies like Photonic Crystals (PCs), Plasmonic, Planar Lightwave Circuits (PLCs) and Micro-Optical-Mechanical Systems (MOEMS). In comparison to above discussed different platform for PICs, photonic crystals-based devices are more preferred because of their various advantages like: ultra-compact in size, more temperature resilient, flexible design structure, low radiation losses, high operation speed and very low group velocity [2].

The photonic crystal structure is micro-nano meter in size with two different dielectric materials, composed into a single substrate to modulate the flow of light in designed structure. Moreover, among various properties of photonic crystals, PCs with aperiodic structure have attracted various 
researcher's attention due to their large range of photonic band gap (PBG), which plays an important role in directing and controlling the flow of light and is considered to be one of the requirements in the implementation of PICs [3].

Basically, PC structure is designed with point defects and line defect to get the photonic band gap (PBG) and these structures could be in the form of 1-Dimensional, 2-Dimensional and 3Dimensional where, 2-Dimensional PC is highly attractive due to the small size, high operating speed, low loss [2]. Based on 2D PC various devices has been designed such as optical waveguides $[4,5]$, optical sensors [6-8], optical filters [9, 10], multiplexer/demultiplexer [11-13], logic gates [14-15], optical switches [16-17], etc. The optical encoders can be designed with three different techniques as self-collimation [18], nonlinear effect [19-20] and interference effect [21-24]. Among these three methods, interference effect method along with coupled mode theory is utilized in this paper, as it can be designed with small dimensions and consumes less power in comparison to self-collimation method which requires phase shifters and designed with large dimensions and also with nonlinear effect, which consumes high power with lower dimensions.

In this work, a novel structure of square ring resonator is proposed and designed to get fast response time and ultra-compact size. There are various numerical methods can be utilized to design PCs, out of which finite-difference-time-domain (FDTD) method is utilized to simulate the structure and to observe the output transmission spectra, electric field view, contrast ratio, delay time, response time and photonic band gap is being calculated by plane wave expansion method, which helped in calculation of frequency bands for transverse magnetic (TM) and transverse electric (TE) modes [25]. 
Present work is structured as: in the next section, proposed design with the working principle of optical encoder along with this photonic band gap structure has been discussed. After that simulation results and analysis has been done along with various parameters of optical encoder as contrast ratio, response time and data rate in comparison to previous work done by researchers. At last conclusion and future work possibilities is discussed.

\section{Proposed encoder design and working principle}

The proposed device using two-dimension photonic crystals (2D PhCs) of square lattice as silicon rods in air structure has been designed. The digital logic encoder is a device with $2^{\mathrm{N}}$ input signals which produces $\mathrm{N}$ bit coded outputs. The encoder has four inputs namely as I0, I1, I2 and I3 and two out ports $\mathrm{Y} 0$ and $\mathrm{Y} 1$, which is shown in figure 1 and truth table which contains its input and output values shown in table 1 . The proposed design contains four linear waveguides namely W1, W2, W3 and W4 and a square ring resonator. Out of these four linear waveguides, four waveguides are working as input waveguides for $4 \times 2$ optical encoder and among these four waveguides, two waveguides W2 and W4, as output waveguide, meeting at output port to Y1 and Y0. Proposed structure is a linear structure, where rod radius is $r=0.1 a$ and lattice constant as $a=540 \mathrm{~nm}$ with dielectric constant of silicon as $\varepsilon=12.04$. The proposed structure parameters discussed in table 2 have been optimized by review analysis on different design aspect as required for band gap calculation, optical integrated circuit and optical encoder applications. Along with this, 6 coupling rods are placed with rod radius of $\mathrm{r} 1=0.07$ a to reduce counter propagation modes and to reduce the scattering loss, four scatter rods have been placed on the corner of ring resonator with radius of $\mathrm{r} 1=0.03 \mathrm{a}$, as shown in figure 2. 


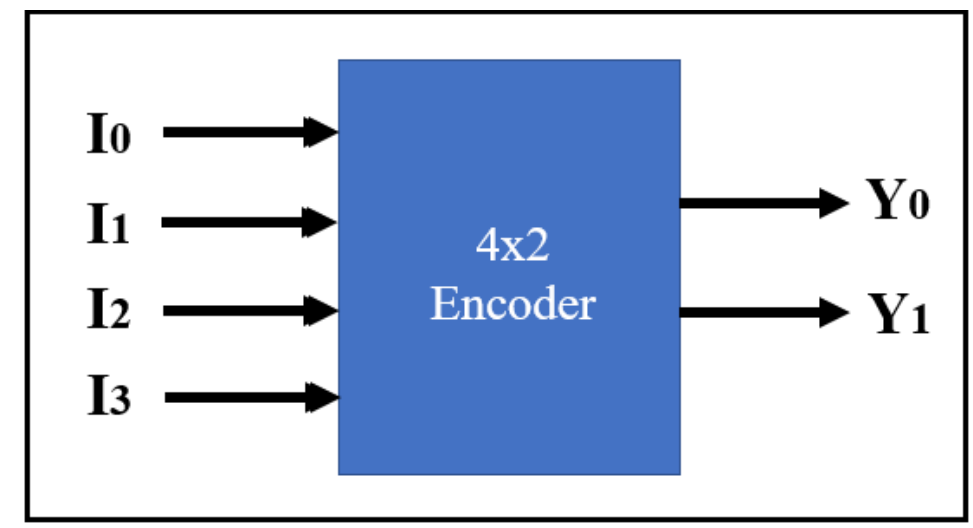

Figure 1: A schematic of $4 \times 2$ optical encoder

Table 1: The 4x2 optical encoder truth table

\begin{tabular}{|c|c|c|c|c|c|}
\hline \multicolumn{5}{|c|}{ Input Ports } & \multicolumn{2}{c|}{ Output Ports } \\
\hline I3 & I2 & I1 & I0 & Y1 & Yo \\
\hline O & 0 & 0 & 1 & 0 & 0 \\
\hline 0 & 0 & 1 & 0 & 0 & 1 \\
\hline 0 & 1 & 0 & 0 & 1 & 0 \\
\hline 1 & 0 & 0 & 0 & 1 & 1 \\
\hline
\end{tabular}




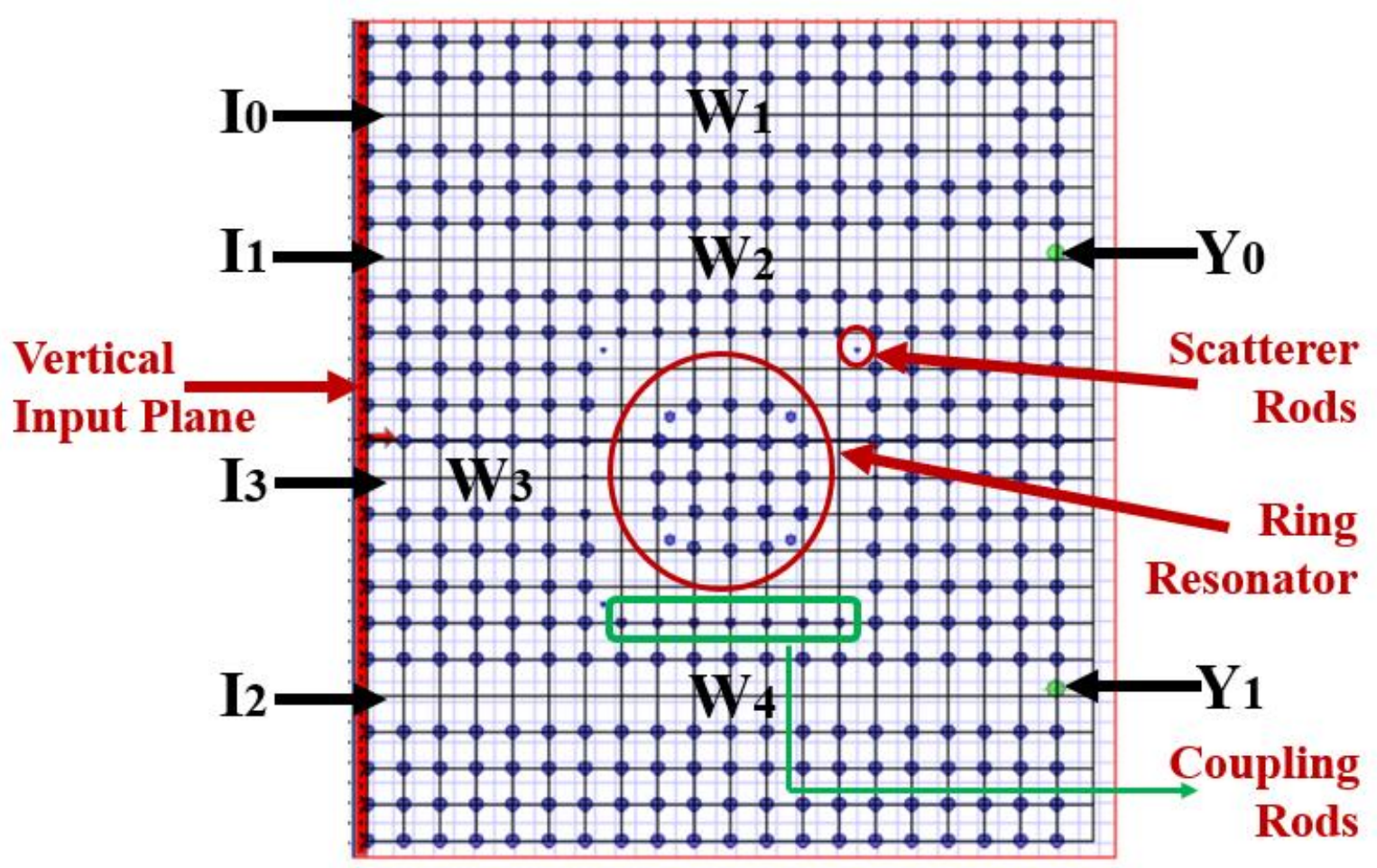

Figure 2: Block diagram of 4x2 optical encoder

\subsection{Working principle}

According to the spatial coupled mode theory (CMT) [26], the amplitudes of waveguide mode in parallel waveguides are interconnected by the equation (1).

$$
\begin{aligned}
& \frac{d A_{1}(z)}{d z}=-j \beta_{1} A_{1}(z)+\kappa_{12} A_{2}(z) \\
& \frac{d A_{2}(z)}{d z}=-j \beta_{2} A_{2}(z)+\kappa_{21} A_{1}(z)
\end{aligned}
$$

where, $A_{1,2}(\mathrm{z})$ is amplitude, $\beta_{1,2}$ is wave vector and $\kappa$ is coupling coefficient. The conservation of energy suggests the coupling coefficients satisfies relation $\kappa_{12}=-\kappa_{21}{ }^{*}$ [ref]. Thus, the absolute value of coupling coefficient is $\kappa \equiv\left|\kappa_{12}\right|=\left|\kappa_{21}\right|$ [26]. Therefore, the propagation coefficients correspond to different modes are given in equation (2) as 


$$
k_{1,2}=\frac{\beta_{1}+\beta_{2}}{2} \pm \sqrt{\left(\frac{\beta_{1}-\beta_{2}}{2}\right)^{2}+\kappa^{2}}
$$

where propagation constant $\mathrm{k}_{1}$ and $\mathrm{k}_{2}$ correspond to odd and even mode. Using such modes, the coupling length of two parallel waveguides is given in equation (3) as

$$
L_{c}=\frac{\pi}{k_{1}-k_{2}}
$$

Using CMT, the coupling length of symmetrical parallel waveguide is given in equation (4) as

$$
L_{c}=\frac{\pi}{2 k}
$$

The amplitude and intensity of propagation mode is function of distance traveled in waveguide (z) and coupling coefficient. So, the amplitude and intensity are expressed in equation (5\&6) as

$$
\begin{array}{lll}
A_{1}(z)=A_{0} \cos (k z) & \text { and } & I_{1}(z)=A_{0}^{2} \cos ^{2}(k z) \\
A_{2}(z)=-i A_{0} \sin (k z) \text { and } & I_{2}(z)=A_{0}^{2} \sin ^{2}(k z)
\end{array}
$$

When the propagation distance is odd integer multiple of coupling length the input single is transferred from waveguide 1 to waveguide 2 .

\subsection{Photonic Band Gap Analysis}

The proposed design of 2D PC structure with silicon rods in air band gap structure has been designed using square lattice ring resonator and here plane wave expansion (PWE) method is utilized to calculate the photonic band gap of designed structure for both TE and TM mode as discussed in table 2 . 


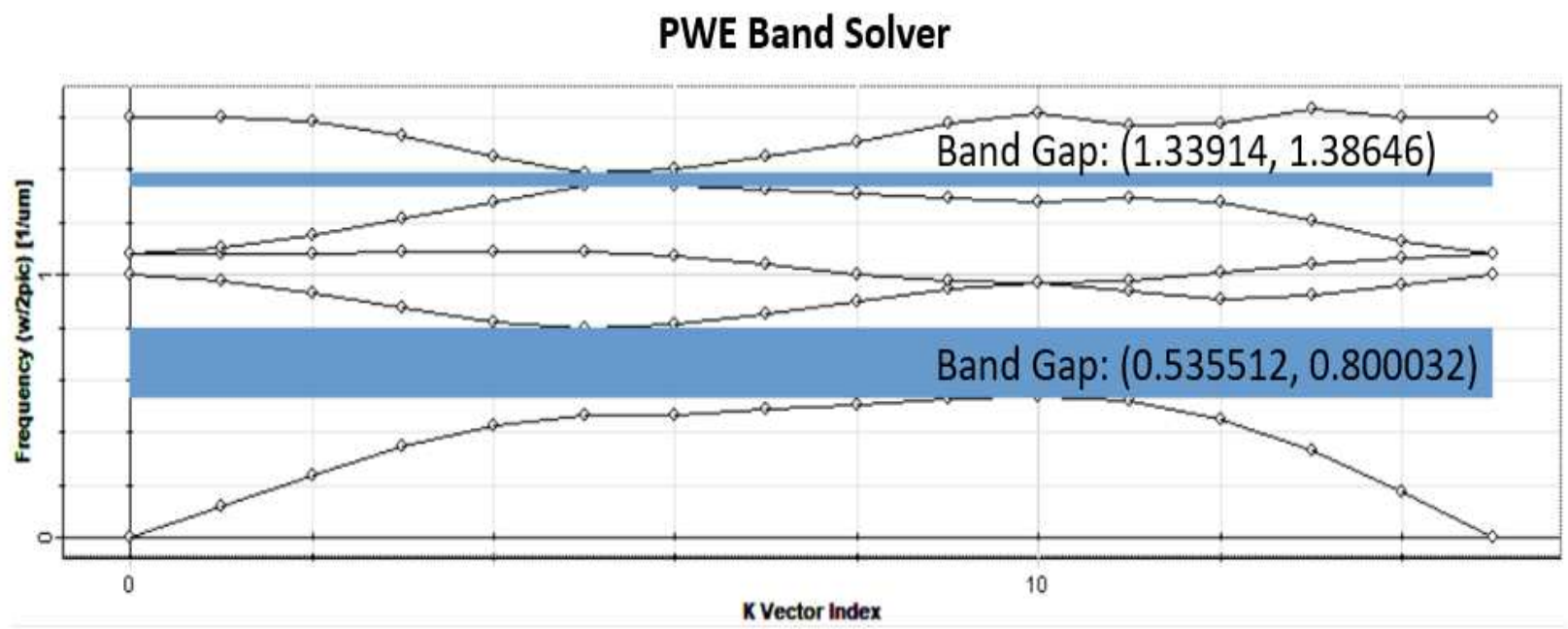

Figure 3. PBG structure of 2D PhC based silicon rods in air structure.

It is shown in figure 3 that two band gaps are existing in TE modes. First photonic bandgap exits from 0.535512 to 0.800032 on wave number scale $\left(\mu \mathrm{m}^{-1}\right)$ or $1249.9 \mathrm{~nm}$ to $1867.3 \mathrm{~nm}$ in wavelength scale, while second photonic band from 1.33914 to 1.38646 on wave number scale $\left(\mu \mathrm{m}^{-1}\right)$ or 721.2 $\mathrm{nm}$ to $746.7 \mathrm{~nm}$. First photonic bandgap is quite wide with width of $617.4 \mathrm{~nm}$ and exits in infrared region, which has good application in optical communication and networks. So, this designed structure with Si material can be utilized for photonic integrated circuits and device application.

Table 2: Parameters used for the proposed optical encoder based on PCRR

\begin{tabular}{|l|l|l|l|}
\hline Designing Parameters & Symbol & Value & Unit \\
\hline Normalized bandgap (TE) & $1 / \lambda$ & $\begin{array}{l}0.535512-0.800032 \\
1.33914-1.38646\end{array}$ & $\mu \mathrm{m}^{-1}$ \\
\hline Normalized bandgap (TM) & $1 / \lambda$ & $1.56981-1.57602$ & $\mu^{-1}$ \\
\hline Centre Wavelength & $\lambda$ & 1550 & $\mathrm{~nm}$ \\
\hline Refractive index of dielectric rods & $\mathrm{nr}$ & 3.47 & - \\
\hline Refractive index of background material & $\mathrm{ns}$ & 1 & - \\
\hline
\end{tabular}




\begin{tabular}{|l|l|l|l|}
\hline Lattice Constant & $\mathrm{a}$ & 540 & $\mathrm{~nm}$ \\
\hline Radius of dielectric rods & $\mathrm{r}$ & $0.1 \mathrm{a}$ & $\mathrm{nm}$ \\
\hline Radius of coupling rods & $\mathrm{r} 1$ & $0.07 \mathrm{a}$ & $\mathrm{nm}$ \\
\hline Radius of scatter rods & $\mathrm{r} 2$ & $0.03 \mathrm{a}$ & $\mathrm{nm}$ \\
\hline Length of waveguide (W1) & $\mathrm{W} 1$ & 10.26 & $\mu \mathrm{m}$ \\
\hline Length of waveguide (W2 and W4) & $\mathrm{W} 1 / \mathrm{W} 4$ & 11.34 & $\mu \mathrm{m}$ \\
\hline Length of waveguide (W3) & $\mathrm{W} 3$ & 3.78 & $\mu \mathrm{m}$ \\
\hline Footprint of the proposed structure & - & 141 & $\mu \mathrm{m}^{2}$ \\
\hline
\end{tabular}

\section{Results and Discussion}

In this section, the electric field views, normalized output power, transmission spectra, delay time, contrast ratio, and response time are calculated using FDTD method. The resonant wavelength is $1550 \mathrm{~nm}$ and for different optical encoder operations, input ports are I0, I1, I2 and I3 from where input light signal is launched and Y0 and Y1 are two output ports, where light signal is received. While observing the transmission spectra, the logic operation states is considered, as transmission spectra output power level is above 0.35 , it is considered as logic ' 1 ', and if output power level is 0.3 or below, it is considered as logic ' 0 '. In the present work, 4 x 2 optical encoder is designed and simulated. For the proposed encoder, four different cases has been studied and accordingly designed structure has been simulated and performance has been analyzed.

Case 1: When $\mathbf{I} 0=\mathbf{1}$ and $\mathbf{I} \mathbf{1}=\mathbf{I} 2=\mathbf{I 3}=\mathbf{0}$, the optical light is launched from input port $\mathbf{I} 0$ and it travels through optical waveguide W1. The separation of three rows of rods between optical waveguide W1 and optical waveguide W2 causes weak coupling between these waveguides. Therefore, the maximum signal is transmitted into waveguide W1 only and a very small parts of the input signal 
couples to waveguide W2. As a result, the signal does not reach at output ports Y0 and Y1, which is shown in figure 4(b). The power level at $\mathrm{Y} 0$ is 0.16 and $\mathrm{Y} 1$ is 0.06 and it is shown in figure 4(a). Therefore, encoder follows $\mathrm{Y} 0=\mathrm{Y} 1=0(\mathrm{OFF})$ condition.

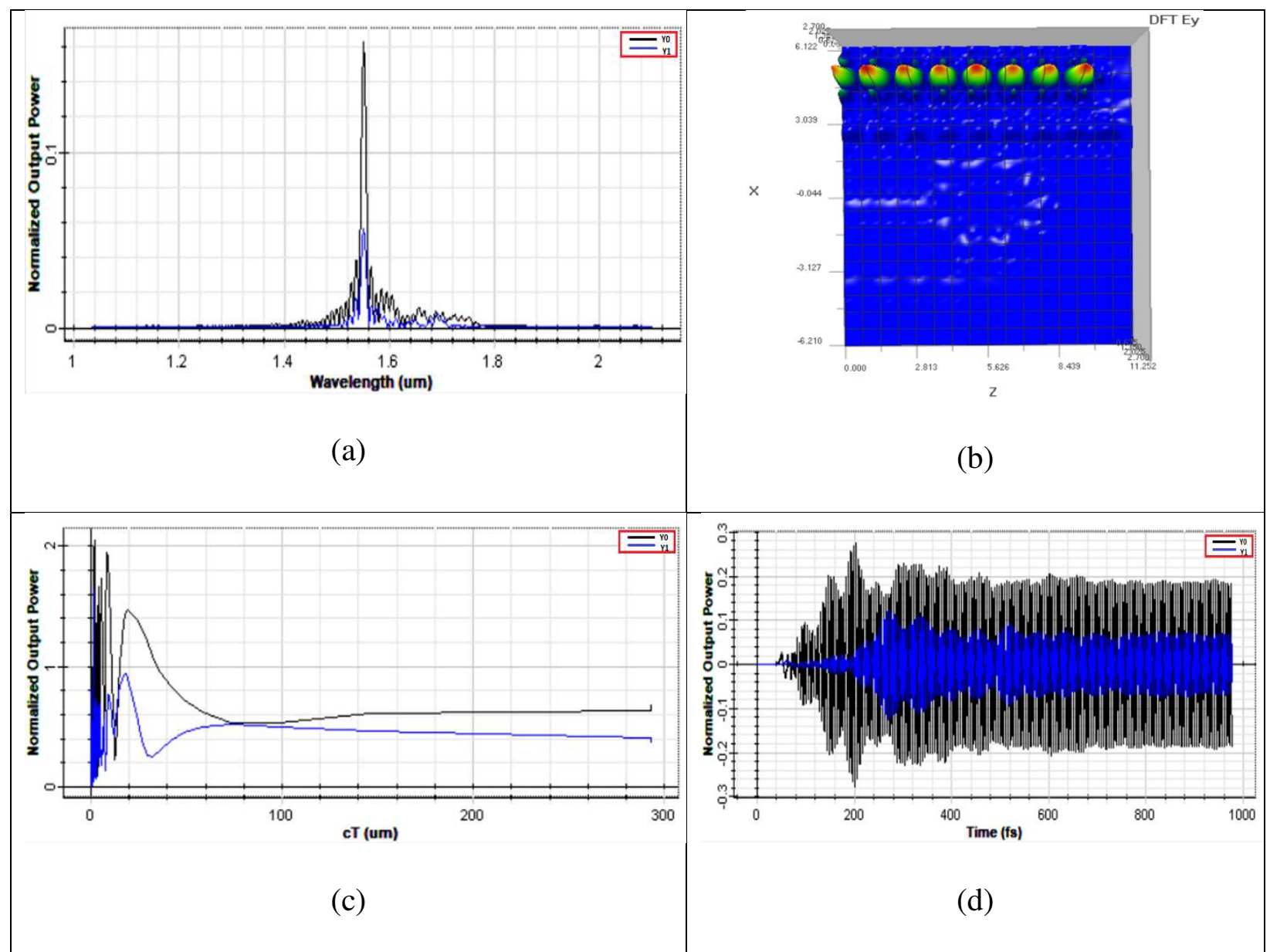

Figure 4. (a) Transmission spectra, (b) Optical signal distribution of inputs 1000, (c) Normalized output power of inputs 1000, (d) The output power level of inputs 1000.

Case 2: When $\mathbf{I 1 = 1}$ and $\mathbf{I 0}=\mathbf{I} 2=\mathbf{I 3}=\mathbf{0}$, the optical light is launched from input port $\mathrm{I} 1$ and it travels through optical waveguide W2. The separation of two rows of rods between optical waveguide $\mathrm{W} 2$ and ring resonator cause weak coupling of signal from waveguide W2 to ring resonator. Therefore, the maximum signal transmitted into waveguide W2 and a very small part couples to ring resonator. As a result, in this case, the signal completely dropped at output port Y0 and a 
smaller amount reached at output ports Y1, which is shown in figure 5(b). The output power level at $\mathrm{Y} 0$ is 1.38 and $\mathrm{Y} 1$ is 0.09 and it is shown in figure 5(a). Therefore, encoder follows $\mathrm{Y} 0=1(\mathrm{ON})$ and $\mathrm{Y} 1=0(\mathrm{OFF})$ condition.

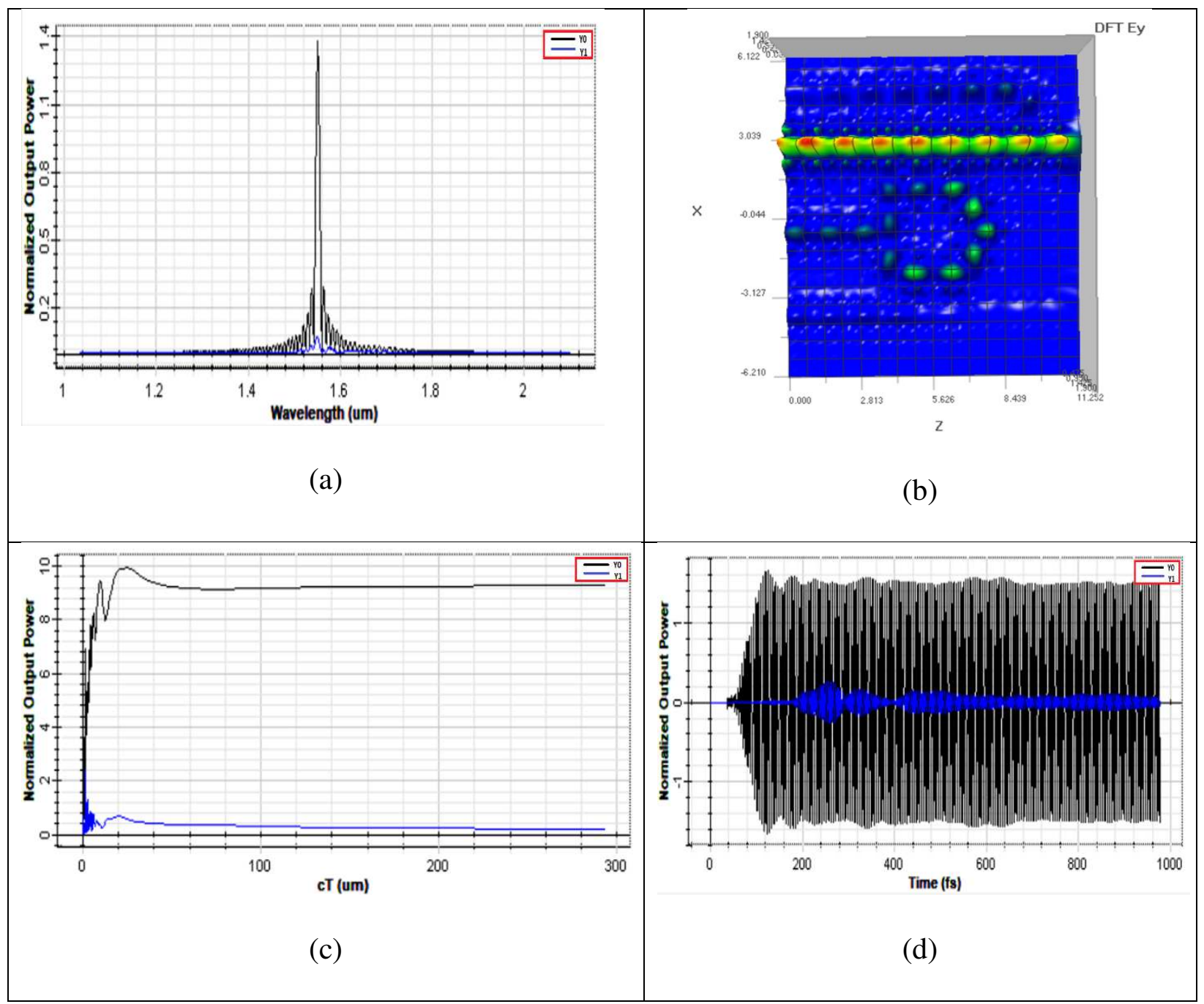

Figure 5. (a) Transmission spectra, (b) Optical signal distribution of inputs 0100, (c) Normalized output power of inputs 0100, (d) The output power level of inputs 0100.

Case 3: When $\mathbf{I} 2=\mathbf{1}$ and $\mathbf{I 0}=\mathbf{I} 1=\mathbf{I 3}=\mathbf{0}$, the optical light is launched from input port $\mathbf{I}$ and it travels to optical waveguide W4. The separation of two rows of rods between optical waveguide W4 and ring resonator cause weak coupling of signal from waveguide W4 to ring resonator. Therefore, the maximum signal transmitted into waveguide W4 and a very small part couples to ring resonator. 
As a result, in this case, signal completely dropped at output port Y1 and a smaller amount reached to output ports $\mathrm{Y} 0$, which is shown in figure $6(\mathrm{~b})$. The power level at $\mathrm{Y} 0$ is 0.08 and $\mathrm{Y} 1$ is 1.3 and it is shown in figure 6(a). Therefore, encoder follows $\mathrm{Y} 0=0(\mathrm{OFF})$ and $\mathrm{Y} 1=1(\mathrm{ON})$ condition.

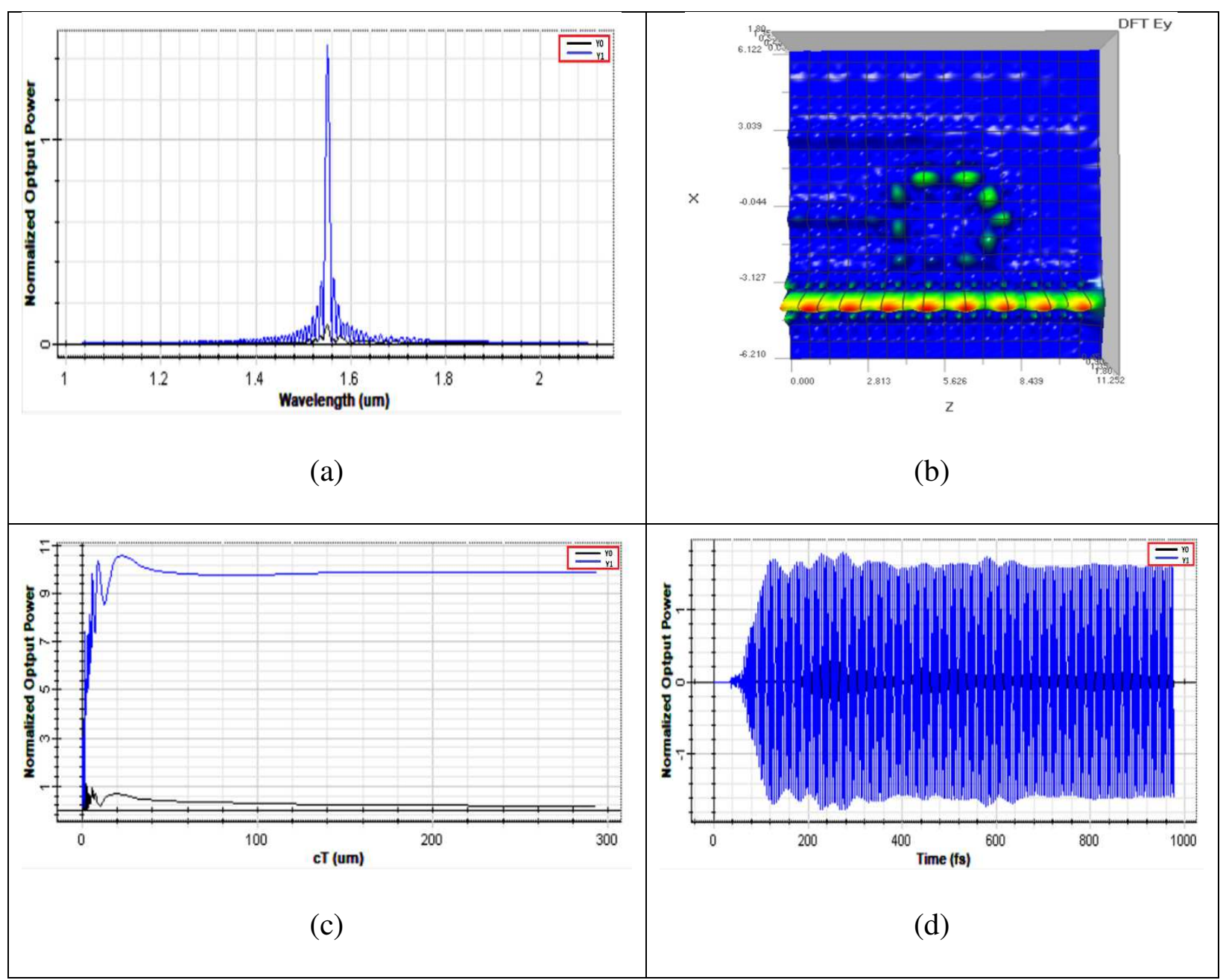

Figure 6. (a) Transmission spectra, (b) Optical signal distribution of inputs 0010, (c) Normalized output power of inputs 0010 , (d) The output power level of inputs 0010.

Case 4: When $\mathbf{I 3}=\mathbf{1}$ and $\mathbf{I} \mathbf{0}=\mathbf{I} 1=\mathbf{I} 2=\mathbf{0}$, the optical light is launched from input port $\mathbf{I} 3$ and it travels to optical waveguide W3. At the start point of ring resonator, the input signal is splitted in to equal parts and travel in ring resonator in opposite direction. As the coupling rods are present on the both side of ring resonator, which causes strong coupling from ring to optical waveguide W2 and W4. 
Therefore, the single reached at output ports $\mathrm{Y} 0$ and $\mathrm{Y} 1$, consequently. As a result, in this case, the signal achieved at both the output ports $\mathrm{Y} 0$ and $\mathrm{Y} 1$, which is shown in figure 7(b). The power level at $\mathrm{Y} 0$ is 0.53 and $\mathrm{Y} 1$ is 0.57 and it is shown in figure 7(a). Therefore, encoder follows $\mathrm{Y} 0=\mathrm{Y} 1=1(\mathrm{ON})$ condition.

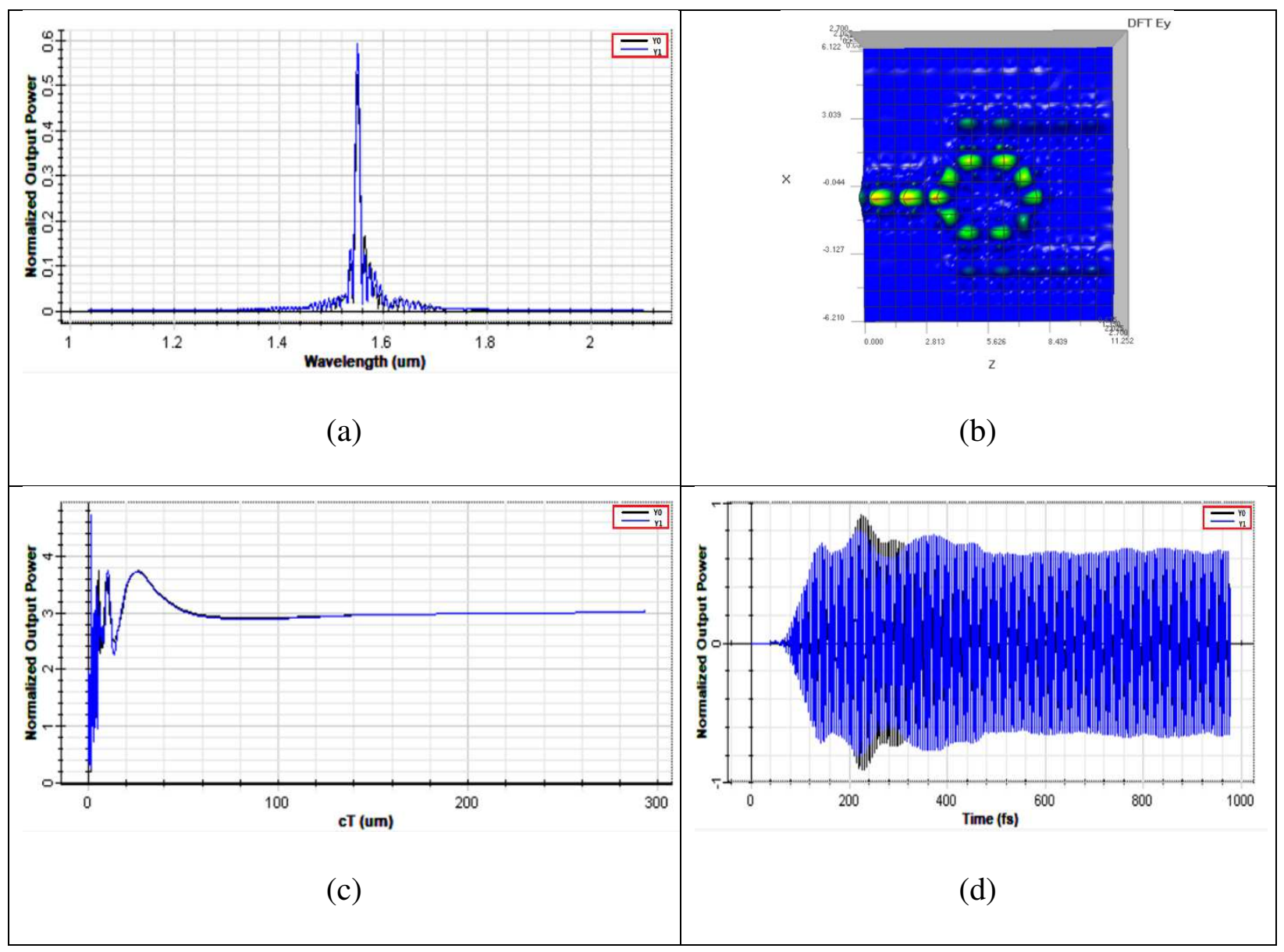

Figure 7. (a) Transmission spectra, (b) Optical signal distribution of inputs 0001, (c) Normalized output power of inputs 0001, (d) The output power level of inputs 0001.

\subsection{Contrast Ratio}

The Contrast Ratio (CR) of the optical encoder is defined in equation (7), as it is the ratio of normalized output power P1 and P0 of logic ' 1 ' to logic ' 0 ', respectively. 
$C R(d B)=10 \log \left\{\frac{P 1}{P 0}\right\}$

where $\mathrm{P} 0$ is the logic ' 0 ' output power and $\mathrm{P} 1$ is the logic ' 1 ' output power.

For the input condition when $\mathrm{I} 1=1(0100)$, the output power level at $\mathrm{Y} 0$ is 1.38 and $\mathrm{Y} 1$ is 0.06 as it is shown in figure 5(a), correspondingly its CR is $11.85 \mathrm{~dB}$. In similar way, for input condition when $\mathrm{I} 2=1(0010)$, the output power level at $\mathrm{Y} 0$ is 0.08 and $\mathrm{Y} 1$ is 1.3 as it is shown in figure 6(a), the calculated CR is $12.10 \mathrm{~dB}$. For the other two cases 00 and 11 of encoder, output response of these logic states are same as it equally distributed, so for these two conditions, CR is not calculated.

\subsection{Response Time and Data Rate}

Apart from contrast ratio (CR), the other two important parameters are as propagation delay and data rate, need to be calculated for logic devices and where data rate is being calculated as reciprocal of response time. As shown the normalized curves in figure 4, 5, 6, and 7 (c and d), the data rate and response time has been calculated theoretically.

For input condition when $\mathrm{Io}=1(1000)$, the response time and data rate is not calculated, as at both the output ports the power level is below 0.3 and output port logic is 00 . For the input condition when $\mathrm{I} 1=1(0100)$, the output port logic is $10(\mathrm{Y} 0=1, \mathrm{Y} 1=0)$, therefore, the delay time calculated as $\mathrm{cT}=22.59 \mu \mathrm{m}$ and its equivalent response time and the data rate is $86.37 \mathrm{fs}$ and $11.57 \mathrm{Tbps}$ from figure 5(c) and 5(d), respectively. For the input condition when $\mathrm{I} 2=1$ (0010), the output port logic is $01(\mathrm{Y} 0=0, \mathrm{Y} 1=1)$, therefore, the delay time calculated as $\mathrm{cT}=$ $22.79 \mu \mathrm{m}$ and its equivalent response time and the data rate is $89.78 \mathrm{fs}$ and $11.13 \mathrm{Tbps}$ from figure 6(c) and 6(d), respectively. For the input condition when $I 3=1(0001)$, the output port 
logic is $11(\mathrm{Y} 0=1, \mathrm{Y} 1=1)$, therefore, the delay time calculated as $\mathrm{cT}=29.76 \mu \mathrm{m}$ and its equivalent response time and the data rate is 222.76 fs and $4.48 \mathrm{Tbps}$ from figure $7(\mathrm{c})$ and $7(\mathrm{~d})$, respectively. The complete performance of $4 \times 2$ encoder is displayed in table 3 .

Table 3: The input signal and performance parameters for the $4 \times 2$ encoder

\begin{tabular}{|c|c|c|c|c|c|c|c|c|}
\hline \multicolumn{4}{|c|}{ Input Ports } & \multicolumn{2}{c|}{ Output Ports } & $\begin{array}{c}\text { Contrast } \\
\text { Ratio (dB) }\end{array}$ & $\begin{array}{c}\text { Response } \\
\text { Time (fs) }\end{array}$ & $\begin{array}{c}\text { Data Rate } \\
\text { (Tbps) }\end{array}$ \\
\hline I3 & I2 & I1 & I0 & Y1 & Yo & - & - \\
\hline 0 & 0 & 0 & 1 & 0.06 & 0.16 & - & 86.37 & 11.57 \\
\hline 0 & 0 & 1 & 0 & 0.09 & 1.38 & 11.85 & 89.78 & 11.13 \\
\hline 1 & 0 & 0 & 0 & 0.57 & 0.53 & 12.10 & 222.76 & 4.48 \\
\hline
\end{tabular}

It is being observed from the table 2, that, maximum delay time is $222.76 \mathrm{fs}$, the minimum contrast ratio is $11.85 \mathrm{~dB}$, and the minimum data rate is $4.48 \mathrm{Tbps}$, respectively.

\subsection{Scatter rod radius analysis}

Scatter rod radius analysis is done in this proposed encoder, where at the inner corners of the ring resonator four scatter rods have been placed. From the simulation results, it has been observed that, these scatter rods influence the efficiency of proposed structure. For optimization, different radius of scatter rods is observed from $0.25 \mathrm{a}$ to $0.35 \mathrm{a}(13 \mathrm{~nm}$ to $18 \mathrm{~nm})$, with a range of $1 \mathrm{~nm}$. In comparison with different scatter rod radius analysis as shown in table 4, with $16 \mathrm{~nm}$ scatter rod radius, encoder has provided optimum power and good contrast ratio for all the logic states of 4x 2 encoder. 
Table 4: Contrast Ratio analysis with scatter rod radius for the $4 \times 2$ encoder

\begin{tabular}{|l|l|l|}
\hline S.No. & Scatter Rod Radius (nm) & Contrast Ratio (dB) \\
\hline 1. & 13 & 12.38 \\
\hline 2 & 14 & 12.25 \\
\hline 3 & 15 & 12.04 \\
\hline 4 & 16 & 12.10 \\
\hline 5 & 17 & 12.24 \\
\hline 6 & 18 & 12.47 \\
\hline
\end{tabular}

The proposed optical encoders performance has been analyzed and compared with previous work done by various researchers around the world and is presented in table 5. The comparative parameters are contrast ratio (CR), response time and footprint of the designed encoder. In one of the research paper authored by Sei-Dargahi [22] shows higher dimensions of $795.6 \mu \mathrm{m}^{2}$, with low response time of 1.8ps. In another paper by Anagha et. al [23] shows the minimum footprint of $218.2 \mu \mathrm{m}^{2}$, where output power is $0.75 \mathrm{~W}$. In the proposed encoder by Naghizada et. al [26] shows higher dimensions of $625 \mu \mathrm{m}^{2}$, but reflects minimum response time of $0.7 \mathrm{ps}$. However, our proposed encoder is designed with good contrast ratio (11.85dB), with fast response time (222.76 fs), high data rate $(4.48 \mathrm{Tbps})$ and ultra-compact size $\left(140.84 \mu \mathrm{m}^{2}\right)$. With the above parameters, it is observed that this device can be utilized for high-speed optical computations. 
Table 5: Comparative analysis with previously designed Optical Encoder

\begin{tabular}{|c|c|c|c|c|c|c|}
\hline References & $\begin{array}{l}\text { Encoder } \\
\text { Type }\end{array}$ & $\begin{array}{l}\text { Lattice } \\
\text { Structure }\end{array}$ & Defects & $\begin{array}{l}\text { Dimensions } \\
\left(\mu \mathbf{m}^{2}\right)\end{array}$ & $\begin{array}{l}\text { Contrast } \\
\text { Ratio } \\
\text { (dB) }\end{array}$ & $\begin{array}{l}\text { Response } \\
\text { Time (ps) }\end{array}$ \\
\hline $\begin{array}{l}\text { Alipour-Banaei } \\
\text { et. al [18] }\end{array}$ & $4 \times 2$ & Hexagonal & $\begin{array}{l}\text { Line and } \\
\text { Point } \\
\text { defects }\end{array}$ & 3795 & 7.84 & 1.4 \\
\hline Iman et. al [19] & $4 \times 2$ & Square & $\begin{array}{l}\text { Ring } \\
\text { Resonator }\end{array}$ & 240.5 & - & - \\
\hline $\begin{array}{l}\text { Gholamnejad et. } \\
\text { al [20] }\end{array}$ & $4 \times 2$ & Hexagonal & $\begin{array}{l}\text { Ring } \\
\text { Resonator }\end{array}$ & 1927 & - & 1 \\
\hline $\begin{array}{l}\text { Seif-Dargahi } \\
{[22]}\end{array}$ & $4 \times 2$ & Square & $\begin{array}{l}\text { Ring } \\
\text { Resonator }\end{array}$ & 795.6 & 9.2 & 1.8 \\
\hline $\begin{array}{l}\text { Anagha et. al } \\
\text { [23] }\end{array}$ & $4 \times 2$ & & & 218.2 & 5.7 & 1 \\
\hline $\begin{array}{l}\text { Naghizade et. al } \\
\text { [27] }\end{array}$ & $4 \times 2$ & Square & $\begin{array}{l}\text { Line and } \\
\text { Point } \\
\text { defects }\end{array}$ & 625 & 15 & 0.7 \\
\hline Moniem [28] & $4 \times 2$ & Square & $\begin{array}{l}\text { Ring } \\
\text { Resonator }\end{array}$ & 1225 & - & 1.9 \\
\hline Proposed Work & $4 \times 2$ & Square & $\begin{array}{l}\text { Ring } \\
\text { Resonator }\end{array}$ & 140.8 & 11.85 & 0.222 \\
\hline
\end{tabular}




\section{Conclusions}

In this paper, $4 \times 2$ optical encoder has been proposed using two-dimensional photonic crystal ring resonator. The optical behavior of encoder is analyzed and simulated using FDTD method and PWE method for photonic band gap analysis. The resonance and coupled mode theory played an important role in designing the encoder. The contrast ratio is $11.85 \mathrm{~dB}$, with switching speed of $4.48 \mathrm{Tbps}$ and ultra-compact size of $140.84 \mu \mathrm{m}^{2}$. Further analysis could be done for different other operating wavelengths and other parameters such as modifying the radius of rods, scatter rod radius or lattice constant. Such kind of device structure with low power consumption, small size and high data rate, which occupy less space could be utilized in future high-speed optical communication networks and photonic integrated circuits.

Funding No financial funding for this work

Conflicts of interest/Competing interests Not Applicable

Availability of data and material Not Applicable

Code availability Not Applicable

\section{References}

[1] E. Yabolnovitch, "Inhibited Spontaneous Emission in Solid-State Physics and Electronics", Phys. Rev. Lett., vol. 58, pp. 2159-2062, 1987.

[2] Shaik, E.H., Rangaswamy, N.: Improved design of all-optical photonic crystal logic gates using Tshaped waveguide. Opt. Quantum Electron. 48, 1-15 (2016). 
[3] J. D. Joannopoulos, R. D. Meade, J. N. Winn, "Photonic Crystals, Molding the Flow of Light", Princeton University Press, Princeton, NJ, 1995.

[4] Otmani, H., et al.: Simulation of magneto-optical properties of magnetic photonic crystal waveguides. J. Nanophoton. 13(2), 026002 (2019).

[5] Mohammadi, M., Seifouri, M.: Numerical investigation of photonic crystal ring resonators coupled bus waveguide as a highly sensitive platform. Photon. Nanostruct. Fundam. Appl. 34, 11-18 (2019).

[6] Radhouene, M., Chhipa, M.K., Najjar, M., Robinson, S., Suthar, B.: Novel design of ring resonator-based temperature sensor using photonics technology. Photon. Sens. 7(4), 311-316 (2017).

[7] Suthar, B., Kumar, N.: Magnetic sensor using extrinsic photonic crystal. Adv. Sci. Eng. Med. 10, 854-856 (2018).

[8] Ankita, Suthar, B., Bhargava, A.: Biosensor Application of One-Dimensional Photonic Crystal for Malaria Diagnosis, Plasmonics 16 (1), 59-63 (2021).

[9] Chhipa, M.K., Radhouene, M., Robinson, S., Suthar, B.: Improved dropping efficiency in twodimensional photonic crystal-based channel drop filter for coarse wavelength division multiplexing application. Opt. Eng. 56(1), 015107 (2017).

[10] Chhipa, M.K., Radhouene, M., Dikshit, A., Robinson, S., Suthar, B.: Novel compact optical channel drop filter for CWDM optical network applications. Int. J. Photon. Opt. Technol. 2(4), 2629 (2016).

[11] Rajasekar, R., Robinson, S.: Nano-channel drop filter using photonic crystal ring resonator for dense wavelength division multiplexing systems. J. Nanoelectron. Optoelectron. 14, 753-758 (2019).

[12] Mohammadi, M., Seifouri, M.: A new proposal for a high performance 4-channel demultiplexer based on 2D photonic crystal using three cascaded ring resonators for applications in advanced optical systems. Opt. Quantum Electron. 51(11), 350 (2019).

[13] Ooka, Y., et al.: Ultrasmall in-plane photonic crystal demultiplexers fabricated with photolithography. Opt. Express 25(2), 1521-1528 (2017).

[14] S. Olyaee, M. Seifouri, A. Mohebzadeh-Bahabady, M. Sardari, Realization of all-optical NOT and XOR logic gates based on interference effect with high contrast ratio and ultra-compacted size, Opt. Quantum Electron. 50 (2018) 1-12.

[15] T.S. Mostafa, N.A. Mohammed, E.S.M. El-Rabaie, Ultra-High bit rate all-optical AND/OR logic gates based on photonic crystal with multi-wavelength simultaneous operation, J. Mod. Opt. 66 (2019) 1005-1016. 
[16] Radhouene, M., Najjar, M., Chhipa, M.K., Robinson, S., Suthar, B.: Design and analysis a thermooptic switch based on photonic crystal ring resonator. Optik 172, 924-929 (2018).

[17] Hoseini, M., Malekmohammad, M.: All-optical high performance graphene-photonic crystal switch. Opt. Commun. 383, 159-164 (2017).

[18] Alipour-Banaei, H., Rabati, M.G., Abdollahzadeh-Badelbou, P., Mehdizadeh, F.: Application of self-collimated beams to realization of all optical photonic crystal encoder. Phys. E Low-dimens. Syst. Nanostruct. 75, 77-85 (2016).

[19] Iman, O., Rafah, N.: A novel all optical $4 \times 2$ encoder switch based on photonic crystal ring resonators. Opt. Int. J. Light Electron Opt. 127(19), 7835-7841 (2016).

[20] Gholamnejad, S., Zavvari, M.: Design and analysis of all-optical 4-2 binary encoder based on photonic crystal. Opt. Quantum Electron 49, 302-314 (2017).

[21] Mostafa, T.S., Mohammed, N.A., El-Rabaie, E.S.M.: Ultracompact ultrafast-switching-speed alloptical $4 \times 2$ encoder based on photonic crystal. J. Comput. Electron. (2018).

[22] Seif-Dargahi, H.: Ultra-fast all-optical encoder using photonic crystal-based ring resonators. Photon. NetwCommun. 36(2), 272-277 (2018).

[23] Anagha, E.G., Rajesh, A., Saranya, D.: Design of an all-optical encoder using 2D photonic crystals. In: 2nd International Conference on Inventive Systems and Control Proceedings, pp. 55-59. IEEE (2018).

[24] Mehdizadeh, F., Soroosh, M., Alipour-Banaei, H.: A proposal for 4-to-2 optical encoder based on photonic crystals. IET Optoelectron.11(1), 29-35 (2017).

[25] Leung, K.M., Liu, Y.F.: Photon band structures: the plane-wave method. Phys. Rev. B 41, 1018810190 (1990).

[26] Boscolo, S., Midiro, M. and Someda, C. G. "Coupling and Decoupling of Electromagnetic Waves in Parallel 2-D Photonic Crystal Waveguides,” IEEE J. Quant. Electron., 38, 47-53, (2002).

[27] Naghizade, S., Khoshsima, H.: Low input power an all optical $4 \times 2$ encoder based on triangular lattice shape photonic crystal. J. Opt. Commun. 42(1), 17-24 (2021).

[28] Moniem, A.: All-optical digital $4 \times 2$ encoder based on 2D photonic crystal ring resonators. J. Mod. Opt. 63(8), 735-741 (2015). 
Figures

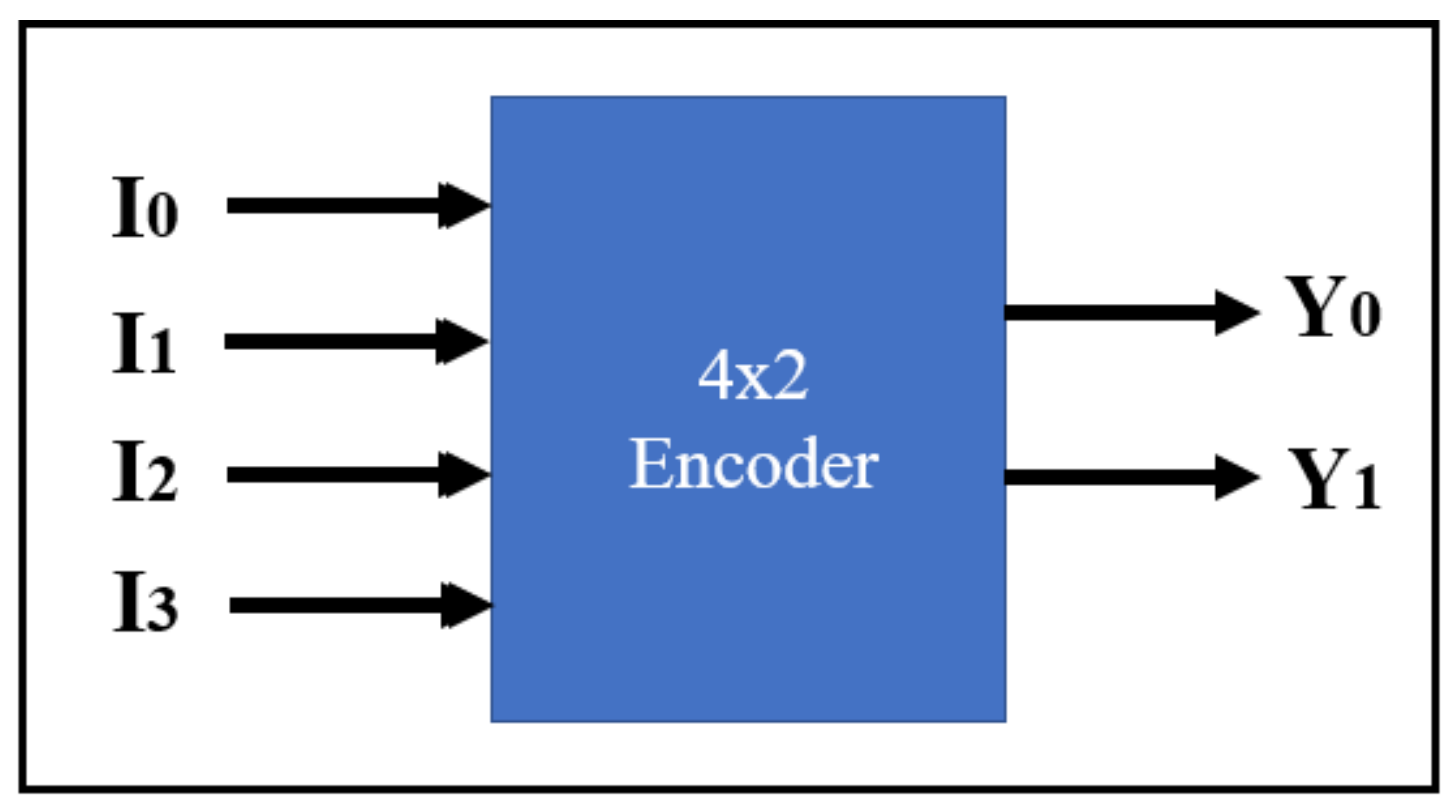

Figure 1

A schematic of $4 \times 2$ optical encoder

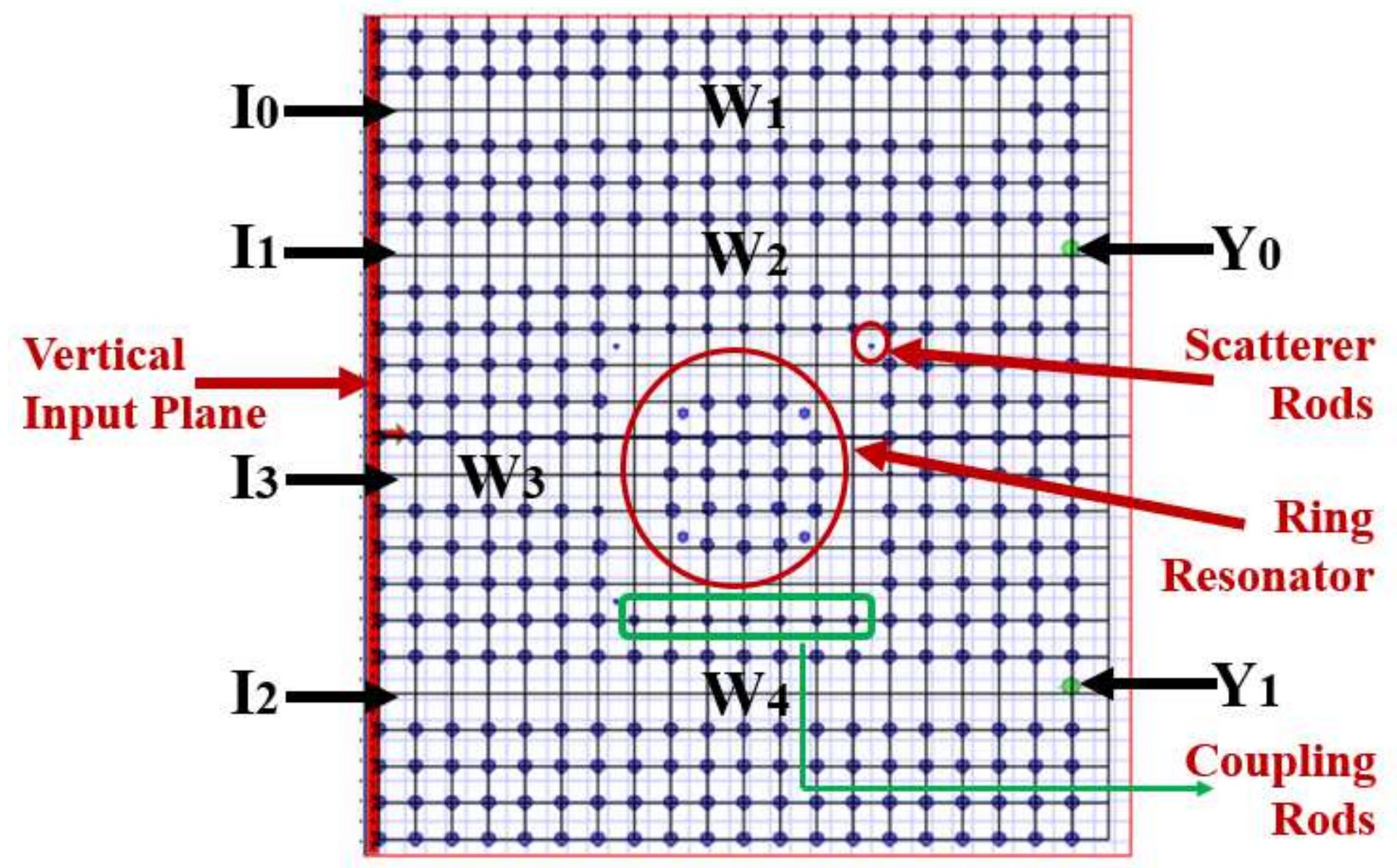

Figure 2 
Block diagram of $4 \times 2$ optical encoder

PWE Band Solver

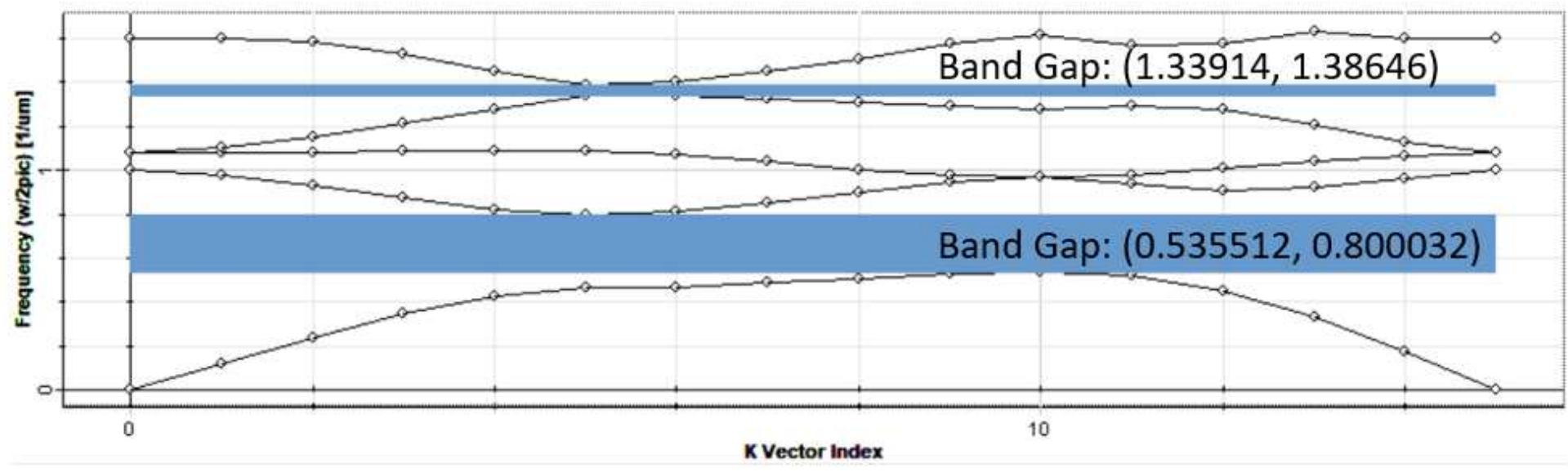

Figure 3

PBG structure of 2D PhC based silicon rods in air structure.

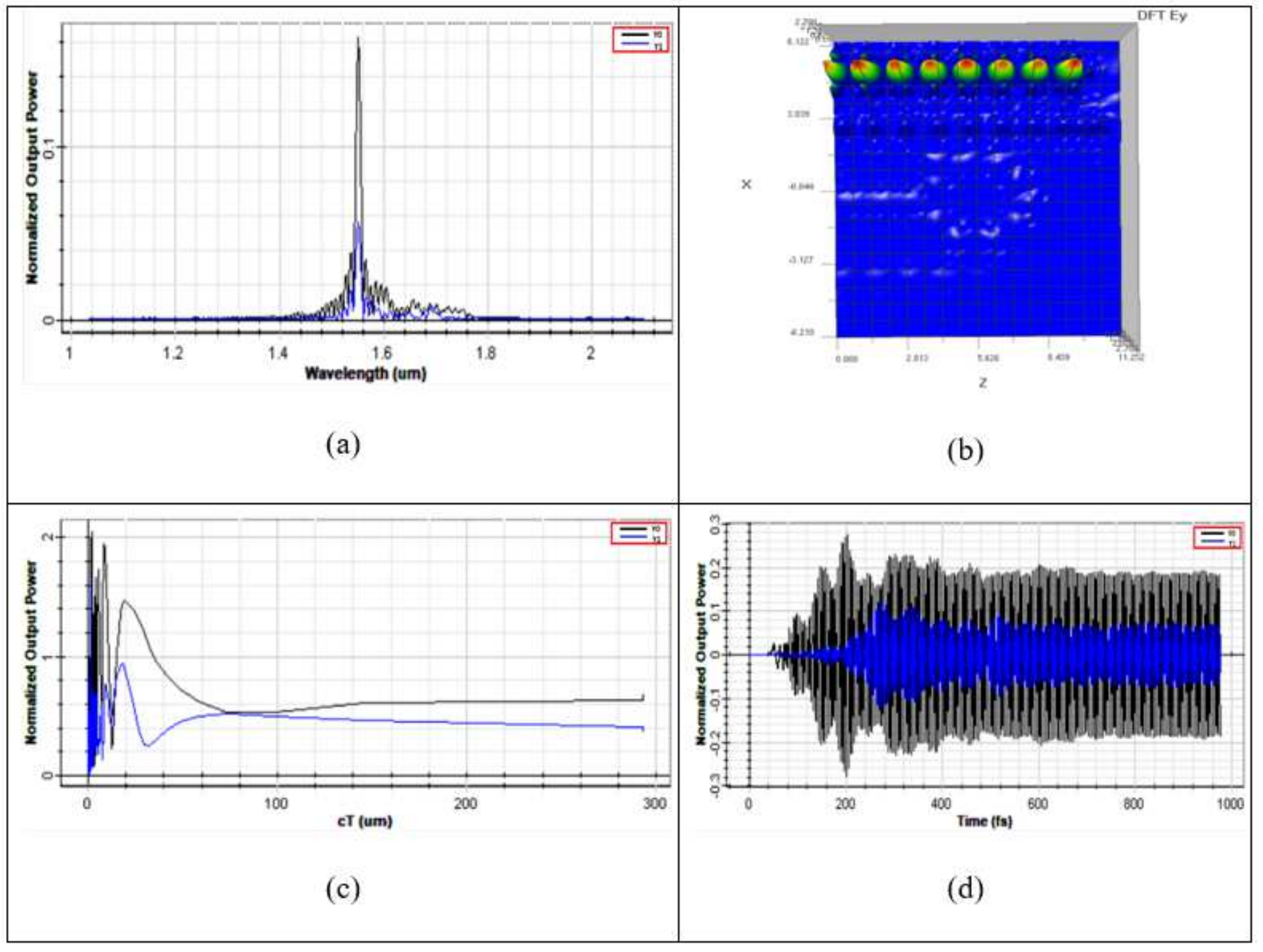

Figure 4 
(a) Transmission spectra, (b) Optical signal distribution of inputs 1000, (c) Normalized output power of inputs 1000, (d) The output power level of inputs 1000.

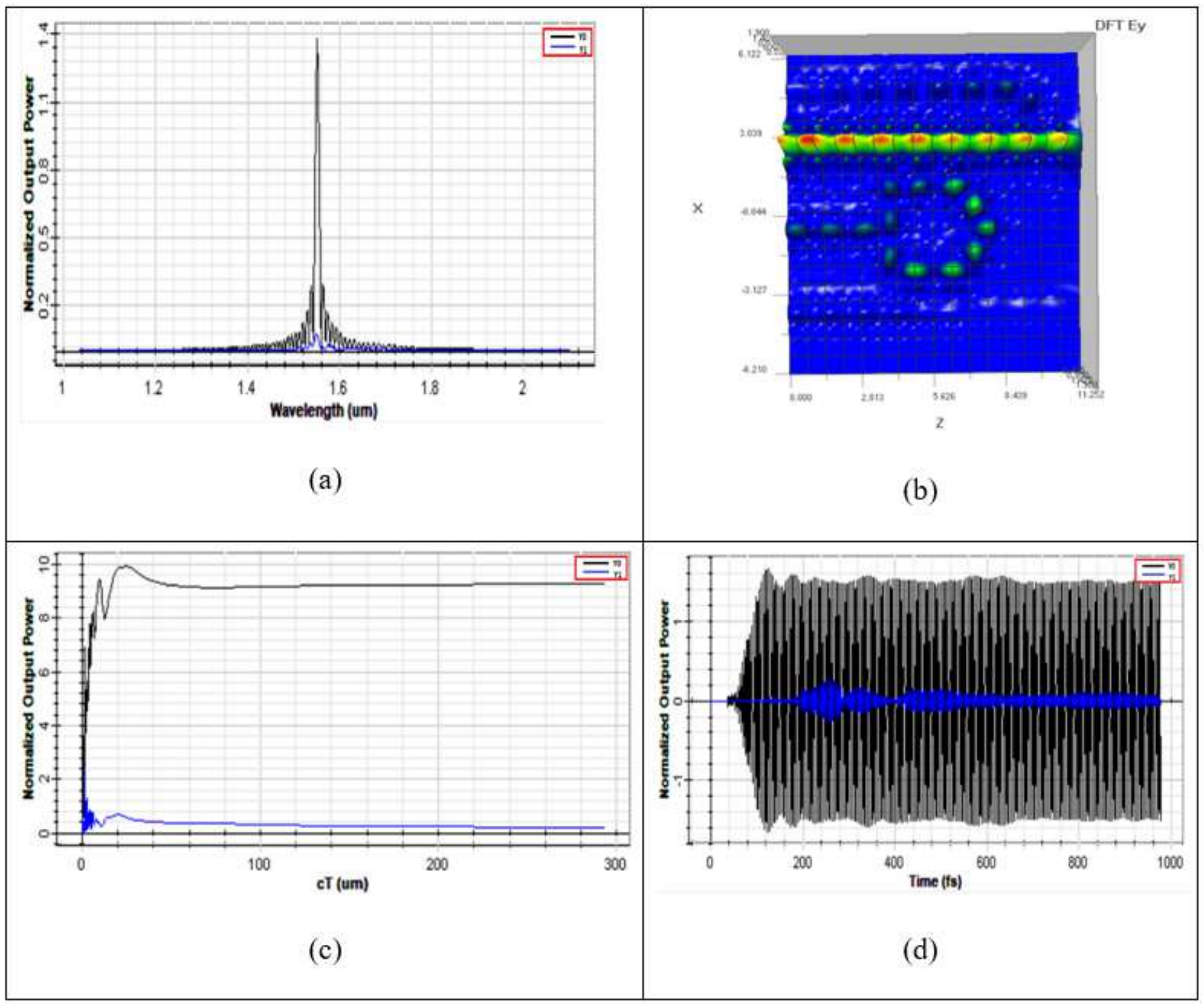

Figure 5

(a) Transmission spectra, (b) Optical signal distribution of inputs 0100, (c) Normalized output power of inputs 0100, (d) The output power level of inputs 0100. 


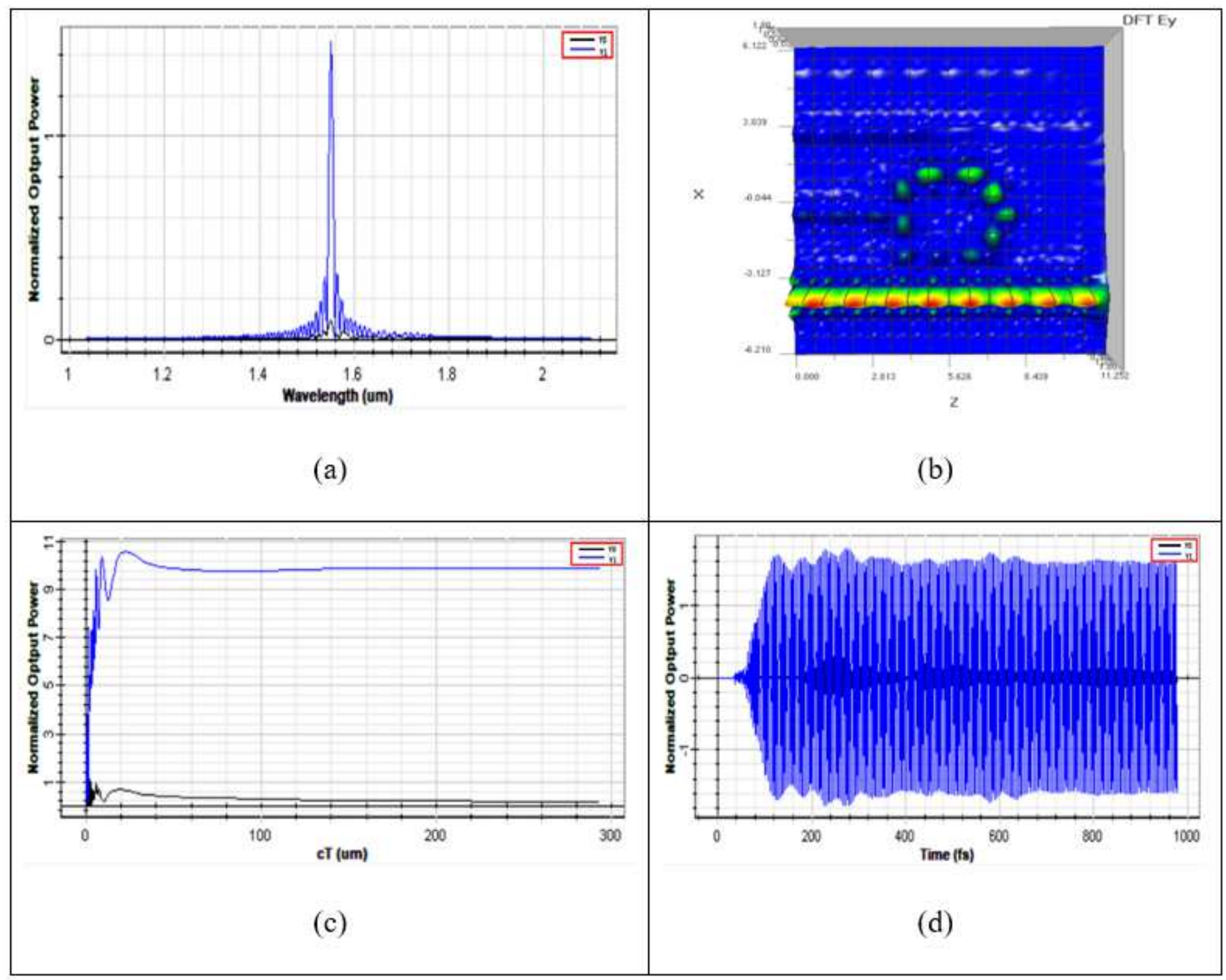

Figure 6

(a) Transmission spectra, (b) Optical signal distribution of inputs 0010, (c) Normalized output power of inputs 0010, (d) The output power level of inputs 0010. 


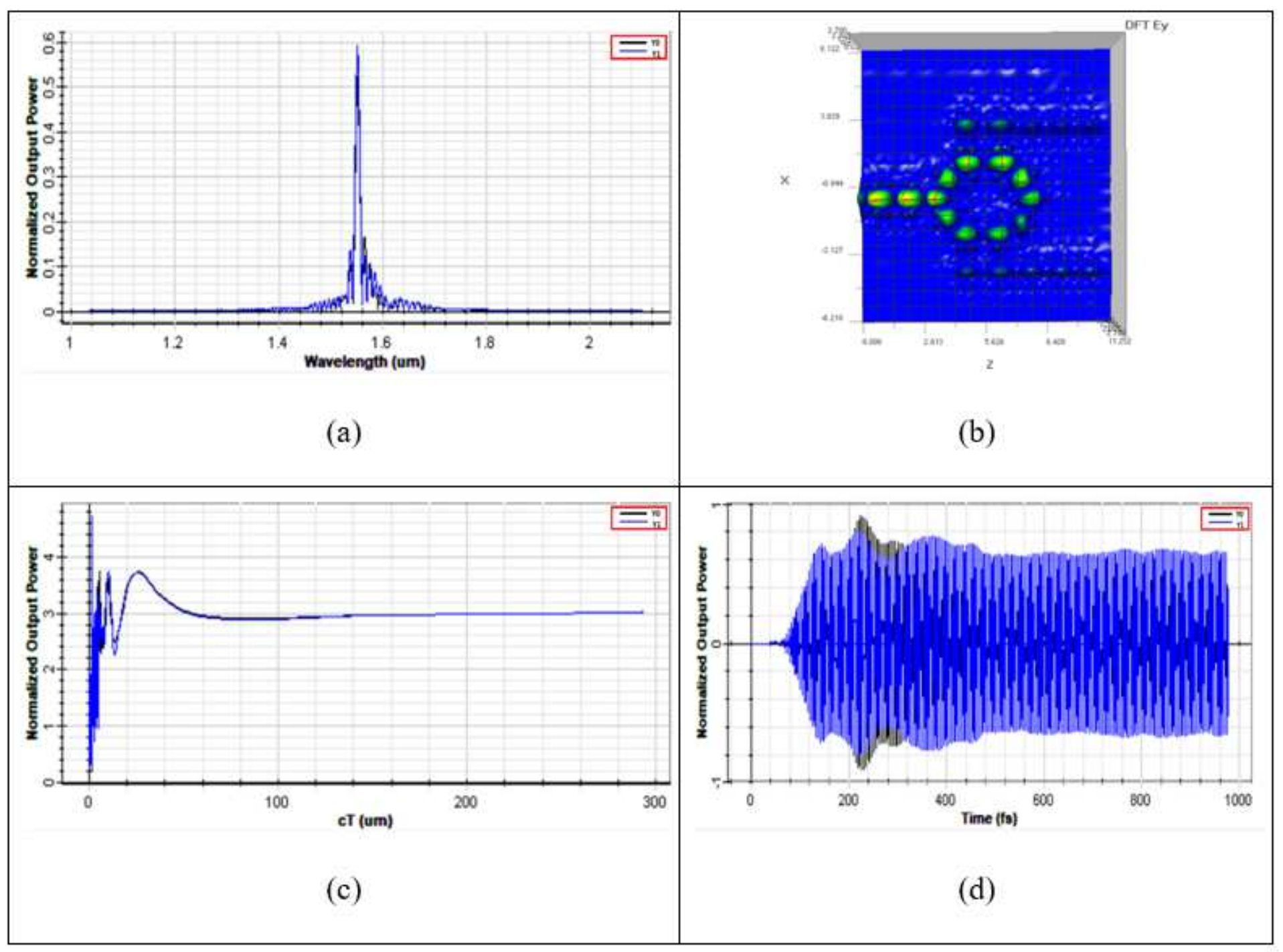

Figure 7

(a) Transmission spectra, (b) Optical signal distribution of inputs 0001, (c) Normalized output power of inputs 0001, (d) The output power level of inputs 0001. 